\title{
LARGE GROUP TEACHING IN THE MEDICAL COLLEGES OF DHAKA CITY
}

\author{
MOHAMMAD $\mathrm{S}^{1}$, MUAZZAM N$^{2}$, HANIF A ${ }^{3}$, TALUKDER HK ${ }^{4}$, HOSSAIN MZ $^{5}$, NAHAR $\mathrm{N}^{6}$
}

\begin{abstract}
This descriptive type of cross sectional study was conducted with the objective to study quality of current practices of large group teaching in selected medical colleges. This study was conducted at different government and non government medical colleges in the year 2007 adopting the convenient sampling using a checklist filled up by participatory observation at 36 lecture classes. The study revealed that the characteristics of the effective lecture are not strictly maintained in the present lecture classes in the medical colleges. Although due to time constraint the study was conducted at limited measure. The study reveals that more than thirty percent of the teachers did not attend any teaching methodology course. The medical colleges are lack in instructional media. More than twenty-seven percent teachers did not mention objectives at the beginning of the lecture. During informal interview some teachers expressed that mentioning objectives at the beginning is wastage of time. Some teacher's expressed that these methodologies of western culture do not fit in the context of Bangladesh due to limited resources, shortage of manpower and over crowding of students. More than eleven percent teachers did not use any visual aid and more than half of the teachers used visual that could not be read from the last bench. Fifty percent of the aid medical teachers do not summarize their lecture at the end. In seventeen percent lecture classes, the students only opened their mouth to respond to the attendance call. The study recommended that all the medical teachers should attend the teaching methodology course as a must. There should be regular visit to the medical colleges lecture galleries informally by authority concerned to ensure the required facilities of lecture classes. Students' evaluation, lecturers' self-rating may really trigger the teachers to identify their deficiencies, and can make real difference. Institute should ensure that teachers are given the support necessary for them to function effectively. Essential audiovisual support should be provided to the teachers for effective delivery of lecture.
\end{abstract}

Key words: Large group teaching, medical college.

J Dhaka Med Coll. 2009; 18(1) : 28-32

\section{Introduction}

Large group teaching is the most predominant teaching methodology in Bangladesh. There are different types of large group teaching Lectures, Symposium, Large group discussions, and Tape slide program. Among other large group techniques lecture is the one, which is commonly applied, in medical colleges. Although curriculum planners wanted to incorporate small group teaching method, integrated teaching method more in the total teaching hour rather than lecture, but still there is a vast amount of lecture hours in the total teaching period. In the academic calendar for anatomy there is grand total of 650 teaching hrs. Among that $120 \mathrm{hrs}$ for lecture, $60 \mathrm{hrs}$ for demonstration, $60 \mathrm{hrs}$ for tutorial, $290 \mathrm{hrs}$ for dissection, $60 \mathrm{hrs}$ for card completion exam and $60 \mathrm{hrs}$ for histology practical. It is the same picture in all other subject. And very interestingly even in clinical subjects such as obstetrics and gynecology course total teaching $\mathrm{hr}$ in 5 th yr is $98 \mathrm{hrs}$, among which $59 \mathrm{hr}$ is taught by lecture method. Lecture saves time and resources, it enables a large amount of information to be presented;

1. Assistant Professor, Dental Public Health, Institute of Medical Technology, Dhaka.

2. Professor \& Head, Department Microbiology, Dhaka Medical College, Dhaka.

3. Assistant Professor, Department of Pediatric Surgery, Dhaka Medical College \& Hospital, Dhaka.

4. Associate Professor, Teaching Methodology, Course Co-coordinator (MMEd), Centre for Medical Education, Dhaka.

5. Assistant Professor, Department of Medicine, Dhaka Medical College \& Hospital, Dhaka.

6. Associate Professor, Department of Pharmacology, East West Medical College, Dhaka.

Correspondence: Dr. Shegufta Mohammad. 
it covers a large group of students. Although this method is very feasible, it has some drawbacks too. A traditional lecture keeps students in a passive situation, creates low receptivity, it does not facilitate problem solving, it offers hardly any possibility of checking the learning process, it does not allow for individual pace of learning ${ }^{12}$. But also to overcome these faults there are instructions. There are steps, by following which one can deliver a successful lecture.

Kenneth R. Stunkel in one of his personal view about lecture described lecture as a powerful tool for intellectual liberation. In his paper he compared and analyzed the interactive teaching method and the age old lecture method subsequently and made his point clear that there is no alternative to a good lecture. A good lecture usually provides opportunities for student comments, questions and sustained dialectical exchange. Discipline for the student consists in listening, remembering, tracking arguments, exercising judgment about notetaking, and thinking about what is said in light of assigned reading. Above all, an objective of such intellectual training is to strengthen attentiveness, without which we can accomplish nothing ${ }^{3}$.

"The successful teacher is no longer on a height; pumping knowledge at high pressure into passive receptacles ... he is a senior student anxious to help his juniors" -William Osler (1849-1919).

So if the lecturer follows the Gagne's theory during lecturing, then he can cover most of the lecturing tips within his control. That's why while preparing the checklist for this study, the researcher tried to incorporate the related steps of Gagne's instructional design 9, 10.

The aim of the study is to determine the level of lectures being given to our future doctors and where the shortcomings are remaining. It is expected that a study of this kind will provide guidelines on further improvement for making lectures a more effective teaching method.

\section{Materials and Methods:}

This was a cross sectional study. The study period was all together one year. A qualitative approach, using participatory observation, was adopted. Among all the public and private medical colleges of Dhaka city, one medical college was selected for pretesting and six other medical colleges including two government and four private medical colleges were selected by convenient sampling for data collection .From each of those six medical colleges, six lectures (two lectures from pre clinical phase, two lectures from Para clinical phase and two lectures from clinical phase) were again selected by convenient sampling. The research Instruments used in the study was three checklists and a personal information form for the teacher. The researcher visited the selected institutes physically and was introduced to the Principal of the colleges and the interest regarding the study was explained and the Principals' permission was sought. After permission was granted by the Principal, the permission of the respective teacher for which lecture is to be observed without disturbing the class were also sought. Checklists were formulated reviewed and pretested and then after necessary modification it was used to collect data by participatory observation and a personal information form of the teacher was filled by the teacher himself after the class or by the researcher by interviewing the teacher. SPSS 11.5 soft ware was used to analyze the data and to show the frequency table.

\section{Results:}

Out of 36 lectures, in 12(33.3\%) lectures the objective was stated at the beginning of the lecture in written form, in $8(22.2 \%)$ lectures the objective was stated verbally, in $6(16.7 \%)$ lectures the teacher discussed the objective vaguely before class and in $10(27.8 \%)$ lectures the teacher did not mention objective of the lecture at all (Table I). Out of 36 lectures, in $3(6.7 \%)$ lectures not a single kind of instructional material was used , in 5 (11.1\%) lectures the teacher used color transparency, in $5(11.1 \%)$ lectures the teacher used black and white transparency, in 16(35.6\%) lectures the teacher used white board, in $9(20 \%)$ lectures PowerPoint was used, in $1(2.2 \%)$ lecture text book was used as instructional material and only in $1(2.2 \%)$ lecture animation 
was used for the students better understanding (Table II). Out of 36 lecture classes, in $7(19.4 \%)$ lectures they were summarized very specifically, in $8(22.2 \%)$ lectures they were roughly summarized, in $3(8.3 \%)$ lectures, there were vague mention of the important points discussed at the end and in $18(50 \%)$ lectures no summarization was done at all (Table III). Out of 36 teachers, 13(36.1\%) used visual aids which were readable from the last bench, 19(52.8) used visual aids which were not readable from the last bench and $4(11.1 \%)$ did not use visuals at all (Table IV). Out of 36 lectures, in 26(72.2\%) lectures the teacher took feedback from the students in $7(19.4 \%)$ lectures to some extent and in $3(8.3 \%)$ lectures the teacher did not take feedback at all (Table V). Out of 36 lectures, in $18(50 \%)$ lecture premises there was instructional aid. In 10(27.8\%) lecture premises the instructional media was up to date, but in $8(22.2 \%)$ lecture premises the media was not in good shape (Table VI). Out of 36 teachers, $25(69.4 \%)$ had exposure of teaching methodology training, and $11(30.6 \%)$ teachers do not have an exposure to such programs (Table VII).

\section{Table- I}

Distribution of lecture classes by level of identification of objective at the beginning of the lecture

\begin{tabular}{lcc}
\hline $\begin{array}{l}\text { Level of identification } \\
\text { of objective }\end{array}$ & Frequency & Percentage \\
\hline In written form & 12 & 33.3 \\
Verbally stated & 8 & 22.2 \\
Vaguely & 6 & 16.7 \\
Not mentioned & 10 & 27.8 \\
\hline Total & 36 & 100 \\
\hline
\end{tabular}

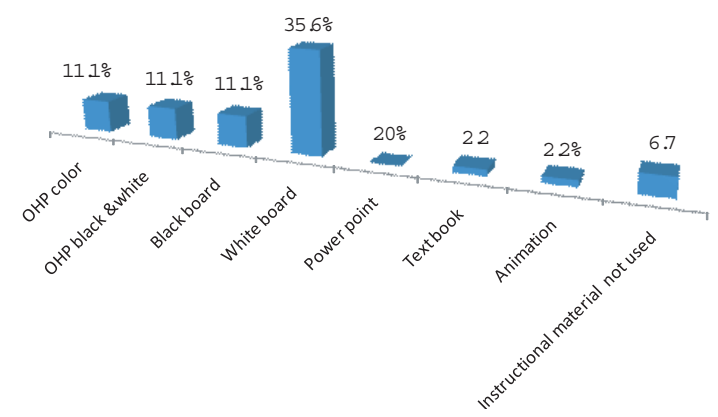

Fig.-1: Distribution of lecture classes by using different instructional materials.
Table- II

Distribution of lecture classes by level of summarization of the whole lecture at the end

Level of summarization Frequency Percentage

$\begin{array}{lll}\text { Very specifically } & 7 & 19.4\end{array}$

$\begin{array}{lll}\text { To some extent } & 8 & 22.2\end{array}$

$\begin{array}{lll}\text { Vaguely } & 3 & 8.3\end{array}$

Not at all $\quad 18 \quad 50$

\begin{tabular}{lll}
\hline Total & 36 & 100
\end{tabular}

Table- III

Distribution of lecture classes by readability of prepared visual aids

\begin{tabular}{lcc}
\hline $\begin{array}{l}\text { Prepared visual } \\
\text { aids were readable }\end{array}$ & Frequency & Percentage \\
\hline Yes & 13 & 36.1 \\
No & 19 & 52.8 \\
Did not use visual aids & 4 & 11.1 \\
\hline Total & 36 & 100 \\
\hline
\end{tabular}

Table- IV

Distribution of teachers by level of taking feedback of the students during the lecture

\begin{tabular}{lcc}
\hline $\begin{array}{l}\text { Level of taking } \\
\text { feedback }\end{array}$ & Frequency & Percentage \\
\hline Constantly & 26 & 72.2 \\
To some extent & 7 & 19.4 \\
Not at all & 3 & 8.3 \\
\hline Total & 36 & 100 \\
\hline
\end{tabular}

Table-V

Distribution of lecture hall by availability of instructional aid

Level of availability $\quad$ Frequency Percentage
of teaching aid

\begin{tabular}{lcc}
\hline Up to date & 10 & 27.8 \\
Adequate & 18 & 50 \\
Not in good shape & 8 & 22.2 \\
\hline Total & 36 & 100 \\
\hline
\end{tabular}


Teachers attended teaching methodology courses/ workshops

Teachers never attended teaching methodology courses/ workshops

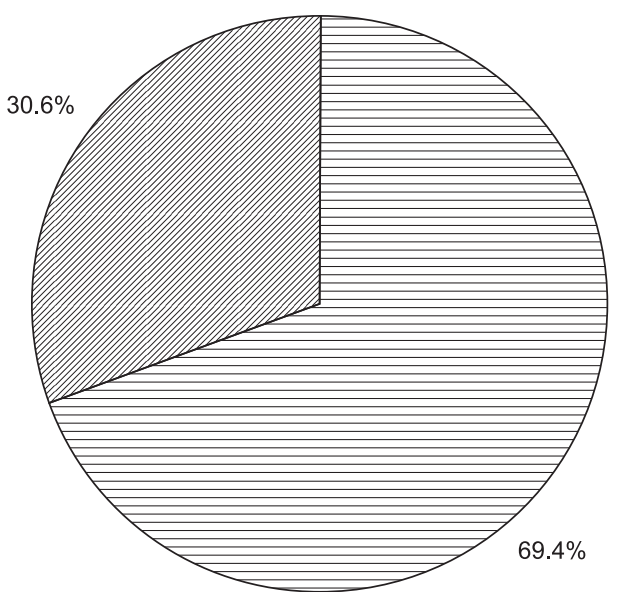

Fig.-2: Distribution of professors/teachers by attending teaching methodology workshop

\section{Discussion:}

Among the observed thirty six lectures, only one third teachers stated the objective of the class in written form. And less than one third took the lecture class without mentioning the objective of the class. After setting clear objectives for each lecture and seminar session with some references, given in handout form to the students at the start of their course, Butler (1992) found out that clearly stated objectives helped them a lot to learn the topic easily $^{4}$. McMillan (2007) shares similar view about setting objectives 56 .

From the study findings, we can see that only $38 \%$ teachers gave importance of recalling the students previous memory by discussing about the preliminary knowledge of the present topic very well and 33\% did not bother at all. Although it is very helpful for the students learning, they just jump started the present topic. The preliminary discussion allows the learners to build up memory on their previous knowledge or skills. Although we are capable of having our "creative" minutes, it is much easier to build on what we already know. e.g. remind the learners of prior knowledge relevant to the current lesson, provide the learners with a framework that helps learning and remembering ${ }^{7}$. We can otherwise mention it as the schema activation. It can be done at the beginning of the lecture by asking question from previous lectures.

Observation shows that more than one third medical teachers prefer white board as instructional material to explain the topic to the students. Only twenty percent prefer power point presentation. There is one possibility that the preparation of power point slides requires much time, and it requires adequate training too. In fact black board is used by more than ten percent teachers. But OHP transparencies are more popular among other instructional material. It may be that it is easy to use, and can be prepared by hand written in fact most of the teachers prepared it by hand. This was sometime not readable from the end of the class

From the results we can see that nearly twenty percent of the teachers summarized the lecture topic at the end of the class. Half of the teachers did not summarize at all. But summarization is very important. The purpose of the lecture summary is to draw together the critical information presented and ensure that students leave the lecture with a clear understanding of this information. The summary should be brief and address only main points. It does not take much time of the lecture period. But still the traditional teachers take it as wastage of time. Evidence suggests that summarizing and linking helps recall and understanding.

Study reveals that more than half of the teachers used visual aids that apparently were not readable from the end of the class. The reason behind this problem was that they used hand written transparency, in which they did not keep in mind about the distance of the last bench of the class. And also when they wrote in the black board it was not that clear because of overuse and while using white board there was often shortage of ink and use of light color pen. Most of the teachers are not exposed to the newer teaching methodology and most of them are not trained to prepare effective instructional material so it is obviously difficult 
for them to select contrast background color in their slides, selecting easy readable font and maintaining appropriate font size. Some of the teachers used transparencies that they have been using for teaching for years so the hand written transparencies faded and it was difficult for the observer to read that from the back of the class. Overall all the teachers who used transparency had so much content on each sheet that it took the students' long time to copy it ${ }^{8}$.

The study reveals that more than half of the lecture classes that have a teacher student interaction there is some humorous story told to the student related to the study topic but in one fourth of the lecture classes there is no interaction of this sort.

Out of 36 teachers, 25(69.4\%) had exposure of teaching methodology training, and $11(30.6 \%)$ teachers do not have an exposure to such programs. But this type of exposure is essential for students learning benefit $9,10,11$.

\section{Limitations:}

Due to time shortage only six lectures per college was selected by convenient sampling but random sampling could have been an appropriate one. The study was focused on the medical colleges of Dhaka city due to the time constrain but it is obvious that the medical colleges situated outside the capital city may have a different picture. The data collection procedure was participatory observation, but as the researcher was observing the lectures given by the most honorable professors and even the principal of each institute advised to seek permission from the respective teachers prior attending the class. So blinding the lecturer was not possible. Still the researcher tried to seek permission of the respective lecturer at the very last moment so that it would not hamper the data.

\section{Conclusion:}

The findings show that effective lecture delivery is less practiced in the medical colleges of Bangladesh. There is also a finding that only $69 \%$ of the teachers of the 36 lectures had attended workshop on medical education and related subject. Through the discussion we find that other studies also share similar findings and in home and abroad there is an urge for change and developing newer concepts and incorporating activities in lecture method. Regular evaluation and training for the teachers are also good approach.

If lecture is more preferable method to teach in the medical colleges, then there should be modification to make it more interactive, effective and use modern instructional material and method and standardizing it according to the international level. Making the teaching methodology course accessible. a must for each and every teacher. Regular informal visit in the lecture halls, student's evaluation, self evaluation and peer evaluation of the lecture classes and related workshops can really make some difference.

\section{References:}

1. Gibbs G, Habeshaw S \& Habeshaw T. Improving student learning during lectures, Med Teach. 1987; 9(1): 11-20.

2. Gulpinar MA \& Yegen BC. Interactive lecturing for meaningful learning in large groups, Med Teach. 2005; 27(7): 590-594.

3. Stunkel KR. The lecture: a powerful tool for intellectual liberation, Med Teach. 1999; 21(4): 424-5.

4. Butler JA. Use of teaching method within the lecture format, Med Teach. 1992; 14(1): 11-25.

5. McMillan WJ. "Then you get a teacher"- Guidelines for excellence in teaching, Med Teach. 2007: 29: e209-18.

6. Tomlinson D. \& Brown G. Improve lecturing, Med Teach. 1979; 1(3): 128-35.

7. Donovan MS \& Bransford JD How Students Learn: History, Mathematics, and Science in the Classroom (Free Executive Summary) http:// www.nap.edu/catalog/10126.html

8. Brow G, Tomlinson D. How to. ..Improve Lecturing Med Teach. 1979; 1(3):

9. Rahman MM. Improving lecture skills for medical teachers in Bangladesh and evaluation by students. [Thesis]. Australia: University of New South Wales; 1997.

10. Ara I. The lecture method in Bangladesh medical school: an appraisal. [Thesis]. Australia: University of New South Wales; 1997.

11. Khan TF. A study on medical college teachers about teaching methodology training 1997-98. [Thesis]. Dhaka: NIPSOM, Univerisity of Dhaka; 2000 . 